\title{
AEROMAGNETIC MAP OF THE ELLINGTON QUADRANGLE AND PART OF THE ROCKVILLE QUADRANGLE, HARTFORD AND TOLLAND COUNTIES, CONNECTICUT
}

\author{
GEOPHYSICAL INVESTIGATIONS \\ MAP GP-648
}

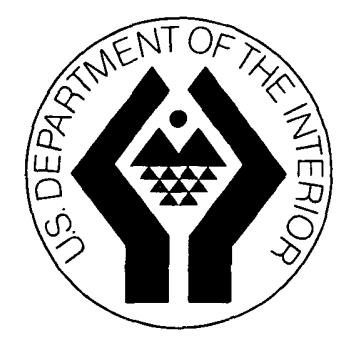

